\title{
Asian Blepharoplasty: The Indian Perspective
}

\author{
Arjun Handa ${ }^{1}$ Shruti Marwah ${ }^{1}$ \\ ${ }^{1}$ Handa Nursing Home, Raja Garden, New Delhi, India
}

\begin{abstract}
Address for correspondence Shruti Marwah, MCh, Handa Nursing Home, 20 Raja Garden, New Delhi 110015, India (e-mail: shrutim150@gmail.com).
\end{abstract}

\begin{abstract}
Keywords

- Asian eyes

- Asian blepharoplasty

- double eyelid surgery

The upper eyelid crease is an indentation at the level where fibers from the levator aponeurosis insert into the skin. Typically, Asian eyes are described as creaseless and puffy and the aim of blepharoplasty is to achieve an eyelid crease, without losing the ethnicity of the individual. We aim to describe the most commonly performed technique as well as the peculiar points to be kept in mind from the Indian perspective.
\end{abstract}

\section{Introduction}

The upper eyelid crease is an indentation of skin at the level of the tarsal border. It is formed by the insertion of distal fibers of the levator aponeurosis into the skin at the level of the superior tarsal border.

Historically, it was thought that East Asians wanted a more Caucasian or Western look and hence opted for double eyelid surgery. However, as Asian literature grew it is now well established that a typical East Asian would dislike a high crease akin to Caucasians and wishes for a crease more suited to their ethnicity. In our experience, the northeastern eyelid and demand for a crease is even more peculiar. This article explores the anatomy and classical description of an Asian blepharoplasty, as well as the peculiar points to be kept in mind from the Indian perspective.

\section{Case Series}

\section{Methodology}

We included 10 patients (19 eyelids) operated between January 2020 and September 2020. All cases were done under local anesthesia. On average, the procedure lasted 75 minutes and patients were discharged the same day. The follow-up period ranges from 2 to 9 months.

\section{Preoperative Stage}

The location of his/her desired eyelid is marked after showing them the mirror which is most commonly 6 to $7 \mathrm{~mm}$ from lid

published online June 28, 2021
DOI https://doi.org/ $10.1055 / \mathrm{s}-0041-1730842$ ISSN 0970-0358 margin. Whether they require an epicanthoplasty as well is determined at this point. An intravenous antibiotic dose of ceftriaxone $1 \mathrm{~g}$ is given before surgery.

\section{Operative Stage}

The steps of procedure were as follows:

- The patient lies supine on table, with parts painted and draped.

- Local anesthesia (2\% lignocaine with adrenaline) is injected. The skin incision is made, and 1 to $2 \mathrm{~mm}$ skin is excised depending upon skin excess (-Fig. 1).

- The space beneath the orbicularis oculi (0O) muscle is dissected using a blunt-tipped instrument.

- The muscle is incised and preseptal fat, if present, is identified and pushed upward.

- The orbital septum lying underneath is identified and incised.

- The preaponeurotic fat is identified and pushed upward using a cotton-tipped applicator.

- The underlying white, shiny structure, that is, the levator aponeurosis is identified (-Fig. 2).

- The 00 muscle is excised to prevent hypertrophy at the skin margin at a later date.

- After achieving hemostasis, three key stitches are taken from lower skin edge to aponeurosis to upper skin edge using 5-0 polyprolene. While taking the stitches, it is important not to take full thickness of the levator in the bite to avoid lid retraction and consequent

(c) 2021. Association of Plastic Surgeons of India.

This is an open access article published by Thieme under the terms of the Creative Commons Attribution-NonDerivative-NonCommercial-License, permitting copying and reproduction so long as the original work is given appropriate credit. Contents may not be used for commercial purposes, or adapted, remixed, transformed or built upon. (https://creativecommons.org/licenses/by-nc-nd/4.0/).

Thieme Medical and Scientific Publishers Pvt. Ltd. A-12, 2nd Floor, Sector 2, Noida-201301 UP, India 


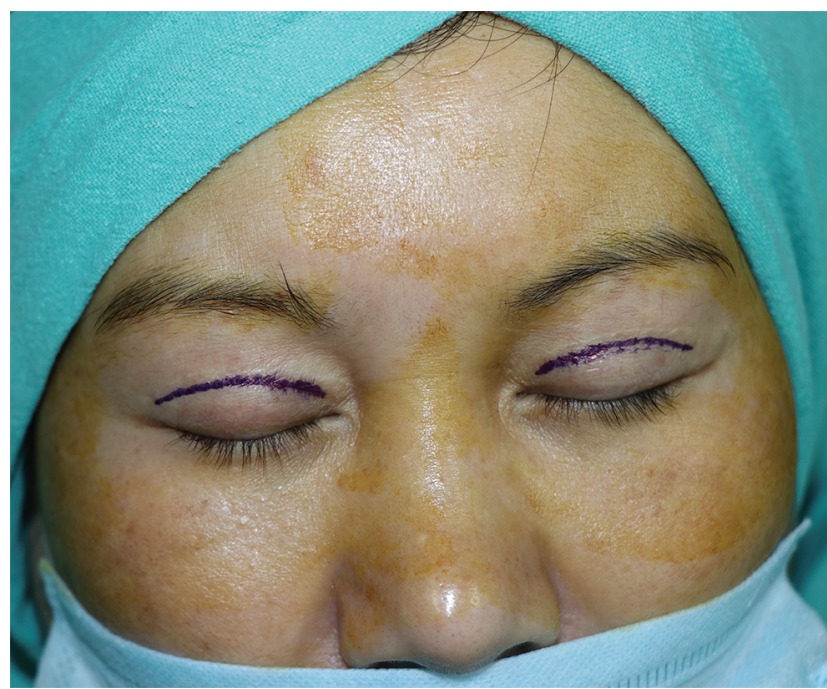

Fig. 1 A typical skin incision marking in a revision case where no skin was excised. (A faint scar of the previous surgery is visible.)

impairment of elevator function. The rest of the skin is closed with 6-0 polyprolene.

Epicanthoplasty: In our cases, simple excision of the epicanthal fold sufficed to achieve the desired result ( - Fig. 3 ).

\section{Postoperative Stage}

The patient is advised cold fomentation and head-end elevation to take care of swelling in the immediate postoperative period. All sutures were removed at the seventh day postoperatively.

\section{Results}

Two of the revision cases achieved the desired lid crease, while both of them had been operated twice earlier. One of them had chosen to undergo revision of the right side only; hence, the aim was to achieve a crease symmetric to the opposite side. Even though in her case the eyelid creases were a bit higher ( $1 \mathrm{~cm}$ from lid margin) than one would like to achieve (-Fig. 4 ).

The rest of the eight cases were primary blepharoplasty with desired results ( $\mathbf{- F i g . 5}$ ).

\section{Anatomy}

Sayoc was one of the first surgeons to discuss the connection between levator palpebrae superioris muscle and the dermis as the anatomic basis for the appearance of supratarsal fold and how this connection was absent in Asian population. ${ }^{1}$ This accounts for a connection that transmits the force vector of levator mechanism to the plate and skin and, therefore, forms the crease. ${ }^{2}$

\section{Discussion}

Surgically created supratarsal fold, also known as the "double eyelid," was first described by Mikamo in $1896 .{ }^{3}$ Typically, the
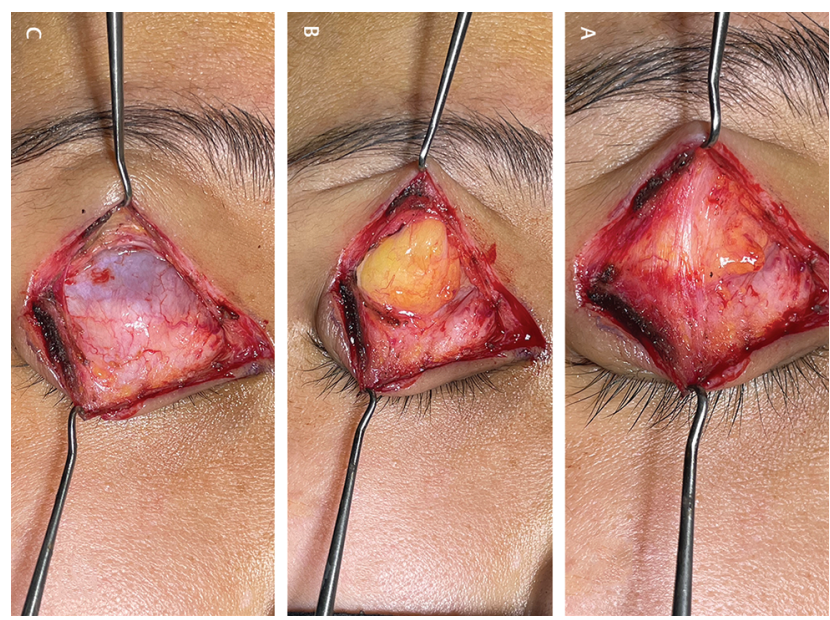

Fig. 2 The figure depicts the following structures: (a) The orbital septum. (b) The septum has been opened and the underlying preaponeurotic fat is visible. (c) The preaponeurotic fat has been trimmed and white, glistening levator aponeurosis is visible.

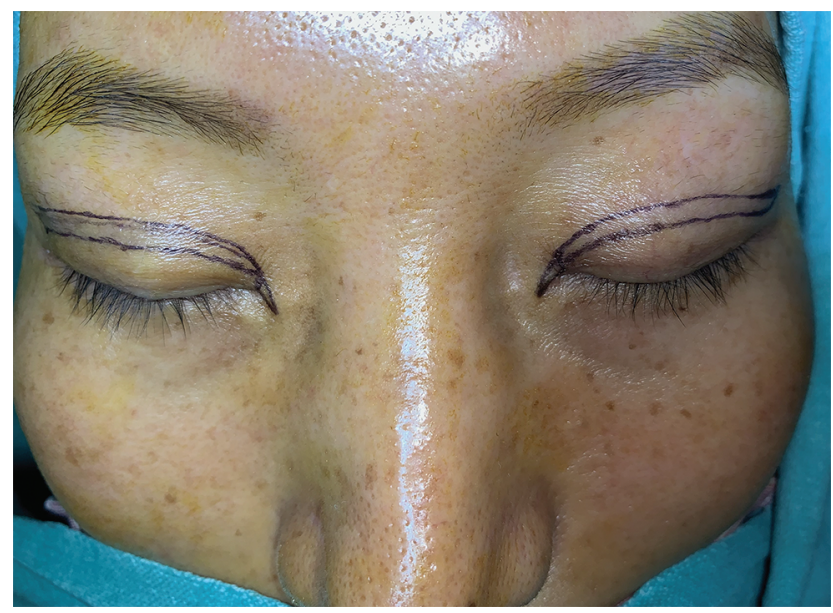

Fig 3 Marking in a patient planned for skin excision of $2 \mathrm{~mm}$ along with an epicanthal fold excision.

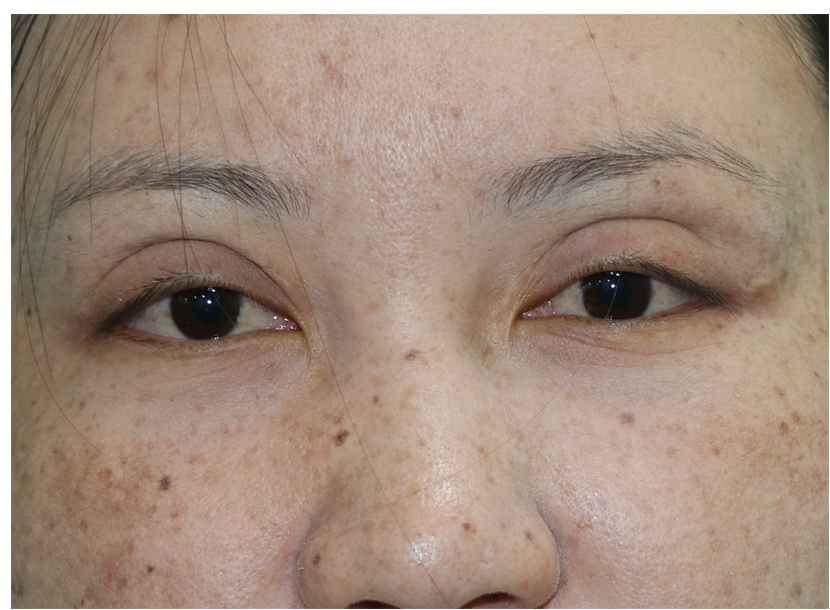

Fig. 4 A high right eyelid crease recreated to achieve symmetry with the opposite side.

Asian eyes are described as creaseless, puffy eyelids with a medial epicanthal fold. The desire for a Caucasian eye stems 


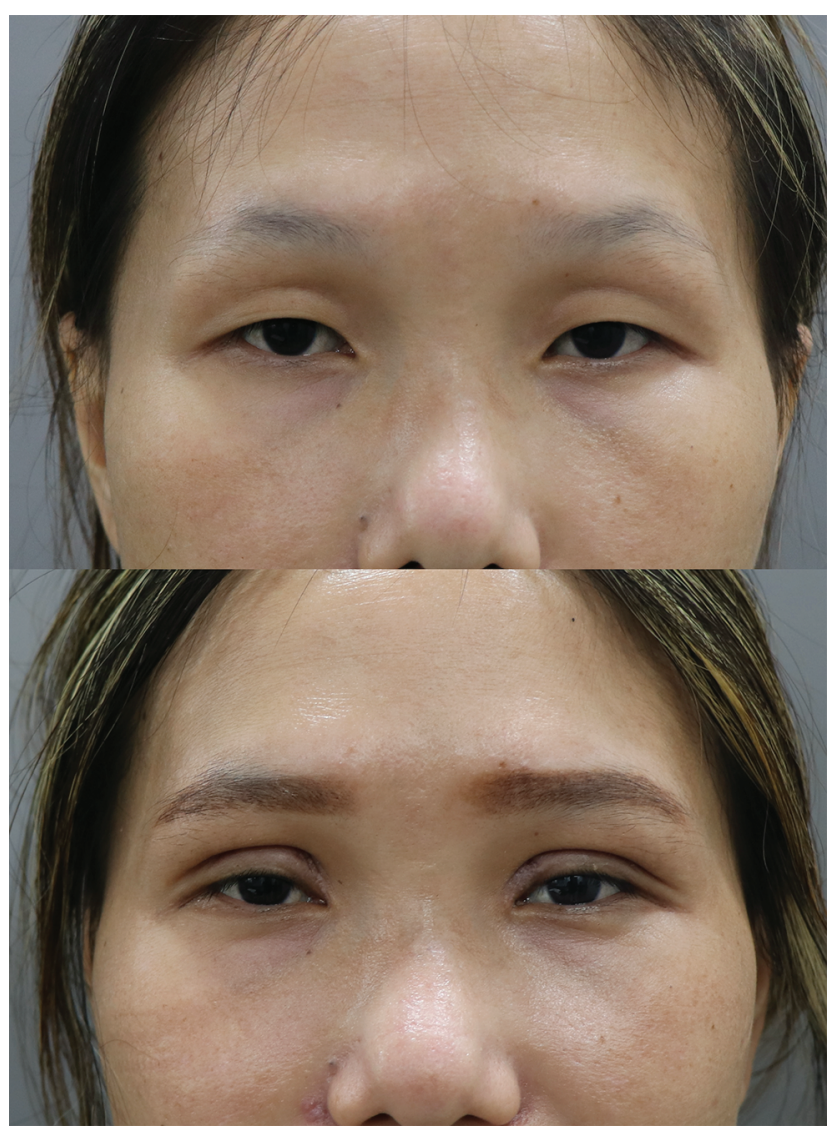

Fig. 5 The before and after results of a primary Asian blepharoplasty at the time of suture removal. Note the swelling in both eyelids ( $R$ > L) that will continue to decrease over the next weeks.

from the want of round eyes which give the perception of bigger eyes. However, it should not come at the cost of losing the ethnicity of the individual. Therefore, the characteristic high-placed eyelid crease which is large and deep would not compliment the typical Asian facial features.

There are three kinds of methods described for creating a double eyelid:

- Nonincision method: It creates an adhesion between the dermis and levator aponeurosis. However, it has a high chance of failure. ${ }^{4}$

- Partial incision method: In this method, one or more small stab incisions are made along the crease to be made. It is considered to overcome the disadvantages of nonincision and incision methods. ${ }^{5}$

- Incision method: This method includes the full incision technique as described earlier. It is the most commonly used method. ${ }^{6}$

Medial epicanthoplasty: A lot of times a fold of skin that is not entirely covering the caruncle is mistaken to be an epicanthal fold. ${ }^{7}$ Various methods include Mustarde's method, vy-plasty, half z-plasty, the inside-out technique, or even simple excision, each with its own merit and demerit. ${ }^{8-10}$

\section{Why Northeast Indian Eyelid May Be Different?}

We observed the following differences from the traditionally described procedure.

- The amount of loose or puffy skin described commonly is relatively less in the northeastern eyelids; hence, it is imperative to calculate the amount of skin to be excised accordingly. If one excises extra skin it may lead to problems like tight skin closure, upturning of the eyelid margin, and in the long-term the sequelae of "old or tired" look due to hollowing of the eyes. Also, it makes revisions difficult.

- The amount of preaponeurotic fat (rarely, preseptal fat) may not be as much in excess as described in the typical "Asian eyes"; hence, excision or reduction may not be required.. Excess reduction may not only be unnecessary but may also contribute to the "old look" due to the resulting hollowing of eyes.

- The pretarsal show desired by our patients is 1 to $2 \mathrm{~mm}$ higher than what is usually described for East Asian patients.

- The need for an extensive procedure for the medial epicanthal fold was not necessary as 8 out of 10 patients were happy with their fold. Two patients desired an increase in size of their palpebral fissure to achieve the look of bigger eyes. However, even in them a simple excision and closure sufficed to achieve the desired result. Thus, it decreased the amount of scar as well as need of small flaps with precarious blood supply.

\section{Conflict of Interest}

None declared.

\section{Acknowledgments}

The authors have no financial interests to disclose.

\section{References}

1 Sayoc BT. Anatomic considerations in the plastic construction of a palpebral fold in the full upper eyelid. Am J Ophthalmol 1967;63(1):155-158

2 Siegel R. Surgical anatomy of the upper eyelid fascia. Ann Plast Surg 1984;13(4):263-273

3 Mikamo M. Mikamo's double-eyelid operation: the advent of Japanese aesthetic surgery. 1896. Plast ReconstrSurg 1997; 99(3):664-, discussion 664-669

4 Choi AK. Oriental blepharoplasty: nonincisional suture technique versus conventional incisional technique. Facial Plast Surg 1994;10(1):67-83

5 Yang SY. Oriental double eyelid: a limited-incision technique. Ann Plast Surg 2001;46(4):364-368

6 Chen WPD. Techniques, principles and benchmarks in Asian blepharoplasty. Plast ReconstrSurg Glob Open 2019;7(5):e2271

7 Johnson CC. Epicanthus. Am J Ophthalmol 1968;66(5):939-946

8 Park JI, Root Z. Root Z-epicanthoplasty in Asian eyelids. Plast ReconstrSurg 2003;111(7):2476-2477

9 Oh YW, Seul CH, Yoo WM. Medial epicanthoplasty using the skin redraping method. Plast ReconstrSurg 2007;119(2): 703-710

10 Seo JD, Kim JH, Pak CS, Heo CY. Medial epicanthoplasty using the "inside-out" technique. J Plast Surg Hand Surg 2014;48(2):139-142 